\title{
Managing Risks Due to Ingredient Variability in Food Production
}

\author{
Frank Riddick $^{1}$, Evan Wallace ${ }^{1}$, and Jim Davis ${ }^{2}$ \\ ${ }^{1}$ National Institute of Standards and Technology, \\ Gaithersburg, MD 20899 \\ ${ }^{2}$ University of California, Los Angeles \\ Los Angeles, CA 90095 \\ frank.riddick@nist.gov \\ evan.wallace@nist.gov \\ jdavis@oit.ucla.edu
}

\begin{abstract}
Managing the design of products and the efficient execution of the manufacturing processes needed to produce them is an endeavor fraught with all manner of risks for manufacturing enterprises large and small. In certain industries, such as the food manufacturing industry, the problems and risks can be even greater. This is because the processes necessary for a food product's manufacture must be designed not only to meet quality, cost, and efficiency targets, but also to have an innate flexibility to cope with the unavoidable variability in the characteristics of the ingredients used to produce the desired product. In the food manufacturing industry and in related industries such as pharmaceutical manufacturing, the problem of identifying vendor sources for ingredients that have acceptable characteristics, managing the acquisition of those ingredients, and then modifying the manufacturing process to cope with the inherent variability in ingredients acquired at different times is an ongoing concern that can expose a company to severe risks.

In this paper, a case study will be presented that illustrates how smart manufacturing (SM) approaches can be applied to reduce the risks due to ingredient variability to, and increase the efficiency of, a food production network. Smart manufacturing integrates bestof-breed solutions from manufacturing and non-manufacturing arenas to solve manufacturing problems and offers great hope for manufacturers. The SM solution described in this paper is built upon what is called the Smart Manufacturing Platform, a software and services platform being developed by the Smart Manufacturing Leadership Coalition.
\end{abstract}

Key words: food production; material variability; risk mitigation; smart manufacturing.

Accepted: January 25, 2016

Published: February 18, 2016

http://dx.doi.org/10.6028/jres.121.002

\section{Introduction}

Managing production in the food manufacturing industry is a complex undertaking. Many of the issues affecting production involve multiple interrelated factors, and often straightforward methods for developing optimal solutions don't exist. These issues include:

- Which finished goods (in what amounts and in what production sequence) should be scheduled for production? This is specified in the production plan.

- What resources, equipment, and staff should be made available to carry out production? This is in the resource schedule and staffing plan.

- What processes and which ingredients should be used to make the best product? This information is specified in the recipe for the product, which contains a specification of how each process will be executed, parameters to control the process, the order in which processes will be executed, and the types and amounts for each ingredient that will be input to each process. There may also be ingredient specifications that define, in detail, the characteristics of ingredients that are acceptable to be used in the recipe as well as the expected characteristics of the final product. 
- Will the ingredients needed for production be available when needed? Are alternate ingredients available to achieve the desired production output and quality if the specified ingredients are not available? This information may be defined in agreements with suppliers and in information about ingredient inventory levels and reorder lead times.

Due to the nature of natural, perishable ingredients used in food production, ingredient variability is unavoidable and must be handled. There are many factors that can cause ingredient characteristics to vary, such as age, vendor/supplier practices, genetic traits, region of origin, growing conditions, soil composition, time of harvest, plant/animal subspecies, crop nutrients/pesticides/herbicides applied, and storage and handling procedures followed. Because of this variability in ingredient characteristics, the final recipe for many food products is often determined at the time of production. To produce products with the desired characteristics, a best practice suggests that manufacturers continually adjust their recipes. These adjustments are often based on the output of sophisticated simulation and analysis tools that take into account variability in the available ingredients. Exacerbating the challenge for food producers, government regulations require that the producer of the final, salable product is responsible for ensuring that all rules about the sourcing, transportation, quality, storage, and handling of ingredients are followed by all players in the supply chain. Consequently, food producers are faced not only with the problem of designing and producing salable food products, they are also tasked with a complex information management problem:

- They need to know about the quality and characteristics of all ingredients that are to be used in production.

- They need to gather and analyze the information in time to:

o make adjustments to the recipe for producing a product using ingredients that are already in inventory or that can be acquired, or

o adjust the production schedule to produce a different product that had been previously planned for production at a different time.

Much of the information needed to support these decisions, when it exists, is often stored in different non-integrated systems, and the exchange of this information may be through hard copy or verbal exchanges over the telephone. Increasing regulatory requirements in the Food Safety Modernization Act (FSMA) [1] with respect to tracking and controls are requiring more stringent and automated tracking, while the increasing use of globally sourced inputs is requiring better capabilities for handling the diversity of input ingredients. This situation is a cause of concern for food manufacturers who want to deliver quality products to their customers while ensuring that all government regulations have been followed.

Today, a new paradigm for manufacturing system design is being applied called smart manufacturing (SM). SM uses advanced information and communications technology (ICT) to enable the integration of existing manufacturing system components and data, the design and introduction of new manufacturing system components, and the adoption of new manufacturing technologies. The goal of SM is to enable manufacturing functions at all levels to exchange the information needed to make critical decisions about the manufacturing enterprise, and to make it possible for the analysis of that information to take place quickly enough so that changes to the operation of the manufacturing enterprise can be implemented based on current conditions. Section 2 presents a brief discussion of SM concepts and how they might be implemented using a common platform.

Section 3 describes an infrastructure platform that can be used as the basis for creating smart manufacturing systems that address manufacturing problems. Section 4 presents a case study where smart manufacturing principles are used to improve the operation of a food production network and to mitigate its risks to production due to ingredient variability. The need for standards to support smart manufacturing is discussed in Sec. 5. The paper concludes with a summary of the work described herein.

\section{The Concept of Smart Manufacturing}

In 2013, U.S. manufacturing output was reported as being worth just over $\$ 2$ trillion, representing over $17 \%$ of the world's total manufacturing output. While impressive, this represents a significant reduction from the United States' 27 \% share of world manufacturing output in 2003. Countries such as India, Korea, 
and China have increased their share, with China capturing over $23 \%$ of the world's manufacturing output in 2013 [2]. The pressure for U.S companies to remain competitive in the global manufacturing arena has never been greater.

Many strategies for increasing a company's manufacturing capability and efficiency have been proposed and are in widespread practice. Just in time (JIT) focuses on reducing inventory and carrying costs; lean manufacturing focuses on reducing and eliminating waste; while Six Sigma focuses on reducing variability in the production process and eliminating product defects. Theory of Constraints (TOC) or Value Stream Mapping (VSM) techniques are used to increase the efficiency of a manufacturer's supply chain. None of these strategies individually or collectively may be enough for U.S. companies to remain competitive.

In an effort to help the competiveness of the U.S. manufacturing industry, President Obama has proposed spending one billion U.S. dollars on a National Network for Manufacturing Innovation. A key part of this plan is "creating a smart manufacturing infrastructure and approaches that let operators make real-time use of 'big data' flows from fully-instrumented plants in order to improve productivity, optimize supply chains, and improve energy, water, and materials use [3].” Related government efforts in smart manufacturing research were already under way at the National Institute of Standards and Technology (NIST) focusing on systems design and analysis and operations planning and control for smart manufacturing systems [4, 5].

Smart manufacturing "is the integration of data with process expertise to enable proactive and intelligent manufacturing decisions in dynamic environments [6]." With respect to products, "the term 'smart' encompasses enterprises that create and use data and information throughout the product life cycle with the goal of creating flexible manufacturing processes that respond rapidly to changes in demand at low cost to the firm without damage to the environment [7].” At its most basic level, smart manufacturing involves applying best-of-breed solutions from product design, manufacturing operations, information technology, modeling and simulation, and supply chain management to optimize the efficiency, productivity, and output of manufacturing systems, plants, and supply networks [8].

The need for smart manufacturing can be highlighted by an examination of some of the current pressures on manufacturers, manufacturers' reactions to these pressures, additional problems precipitated by the reactions, and how these problems could be mitigated through the application of smart manufacturing solutions. The traditional pressures faced by manufacturing enterprises have not gone away including how to make products customers want, how to maintain quality while controlling costs, and how to construct and manage robust yet efficient supply chains. These pressures have been exacerbated by globalization and the speed of technological change. Worldwide financial problems have amplified demand and commodity price fluctuations [9]. Political unrest and natural disasters have disrupted supply chains [10-12]. Technological innovations have so changed the way people and businesses communicate (e.g., mobile communication and the Internet of Things) and the way products can be produced (e.g., 3D printing, advanced robotics, and advanced materials) that they are deemed disruptive [13].

Companies continue to respond to these disruptions in much the same way as they have in the past. At the strategic level they have adopted widely followed manufacturing strategies such as Six Sigma or lean. At the tactical operations level they have shortened product lead times and increased product variety to deal with smaller marketing windows due to changing customer demand. To support these responses, they have deployed enterprise and/or production level software applications and suites.

While these responses have been met with some success, a result is that many manufacturers have a complexly interconnected collection of legacy business and manufacturing systems. This leads to reduced flexibility, increased costs, lost market opportunities, and the inability to take advantage of new techniques or technologies [10]. Smart manufacturing is an attempt to break out of the traditional mode of thinking about, and designing, strategies for manufacturing enterprises, systems, and infrastructure. It seeks to support systems and strategies that move manufacturing "from reactive to proactive, response to prevention [9].” 


\section{The SMLC’s Smart Manufacturing Platform}

Enabling the deployment of smart manufacturing solutions requires an infrastructure to support the development of those solutions and the integration of those solutions with the existing manufacturing environment. To meet these needs, the Smart Manufacturing Leadership Coalition (SMLC) is developing an open-architecture, shared infrastructure called the Smart Manufacturing Platform (SM Platform) ${ }^{1}$. The SMLC is a non-profit organization committed to improving manufacturing competitiveness through the adoption of smart manufacturing technology. Reported in Davis, Wetzel, and Graybill [14], the SMLC contends there are ample opportunities to apply the SM Platform across multiple manufacturing industries including oil and gas, chemical, metal, glass, pharmaceutical, automotive, aerospace, food, and defense. These opportunities exist at different operational layers - automation, operations, enterprise, and supply chain management.

In the SMLC's view, SM is the sophisticated practice of generating and orchestrating the use of datadriven manufacturing intelligence using multiple real-time SM Systems pervasively deployed throughout all operating layers (i.e., control, automation, maintenance/reliability, operations, logistics, risk management, and business management) across the entire factory and supply chain [15]. At its technical core, the SM Platform supports or interfaces with systems that can define what data is collected and shared; how the results of the analysis of that data can be interfaced with operating equipment and automation infrastructures; and how the results are displayed in an actionable form to operators, engineers, and managers.

Workflow ${ }^{2}$, along with the concept of Workflow as a Service (WfaaS), is a key foundational mechanism of the SMLC SM Platform [14]. The Workflow Management Facility developed by the Workflow Management Coalition and the Object Management Group states, "Workflow is concerned with the automation of procedures where information and tasks are passed between participants according to a defined set of rules to achieve, or contribute to, an overall business goal [16].” These participants can be people, systems, or software agents. WfaaS provides the functions of a workflow management system such as workflow process definition and workflow execution as services on a cloud infrastructure. It provides a foundation for orchestrating dynamic, adaptive, actionable decision-making through the contextualization and understanding of data across enterprise functions and throughout the manufacturing process. An emphasis on workflow empowers an enterprise to: formalize/standardize operating procedures not only for operations but also for maintenance, transportation, inventory management, and the supply chain; automate the gathering, transformation, and distribution of data about enterprise operations so that the business functions of the enterprise can use it; automate and monitor the execution of the now standardized operation procedures to ensure the efficient execution of those procedures; and enable easier creation, testing, and deployment of new/modified operating procedures without disruption to other enterprise operations.

Figure 1 graphically describes the seams at layers of manufacturing operations and at stages of a product lifecycle that the cloud-based WfaaS capability is designed to bridge. On the right, it depicts functions and components of the SM Platform, and the dotted arrows depict how the workflows in the platform relate to manufacturing functions and data.

The SM Platform has an open architecture that includes a workflow execution engine, compute and storage resources, and an app store to contain software applications and workflow toolkits. The goal of the SM Platform is to provide an infrastructure to better enable small, medium, and large companies to create smart manufacturing solutions at an affordable cost. The SM Platform will create a capitalization and commercialization pathway for technology infusion and commercialization. This will facilitate a sustainable business and financial roadmap through enabling a broad base of innovators such as third-party application developers to participate in an "App Store" community. The SM Platform will be IT-provider and production-technology agnostic, thereby making sharing of applications and deployment capabilities

\footnotetext{
${ }^{1}$ Commercial equipment and materials might be identified to adequately specify certain procedures. In no case does such identification imply recommendation or endorsement by the U.S. National Institute of Standards and Technology, nor does it imply that the materials or equipment identified are necessarily the best available for the purpose.

${ }^{2}$ While Business Process Management (BPM) suites provide the capabilities discussed here and more, this paper is not concerned with the broader functionality of BPM and thus employs the term workflow to refer only to process definition and execution.
} 


\section{SM Platform Architecture}

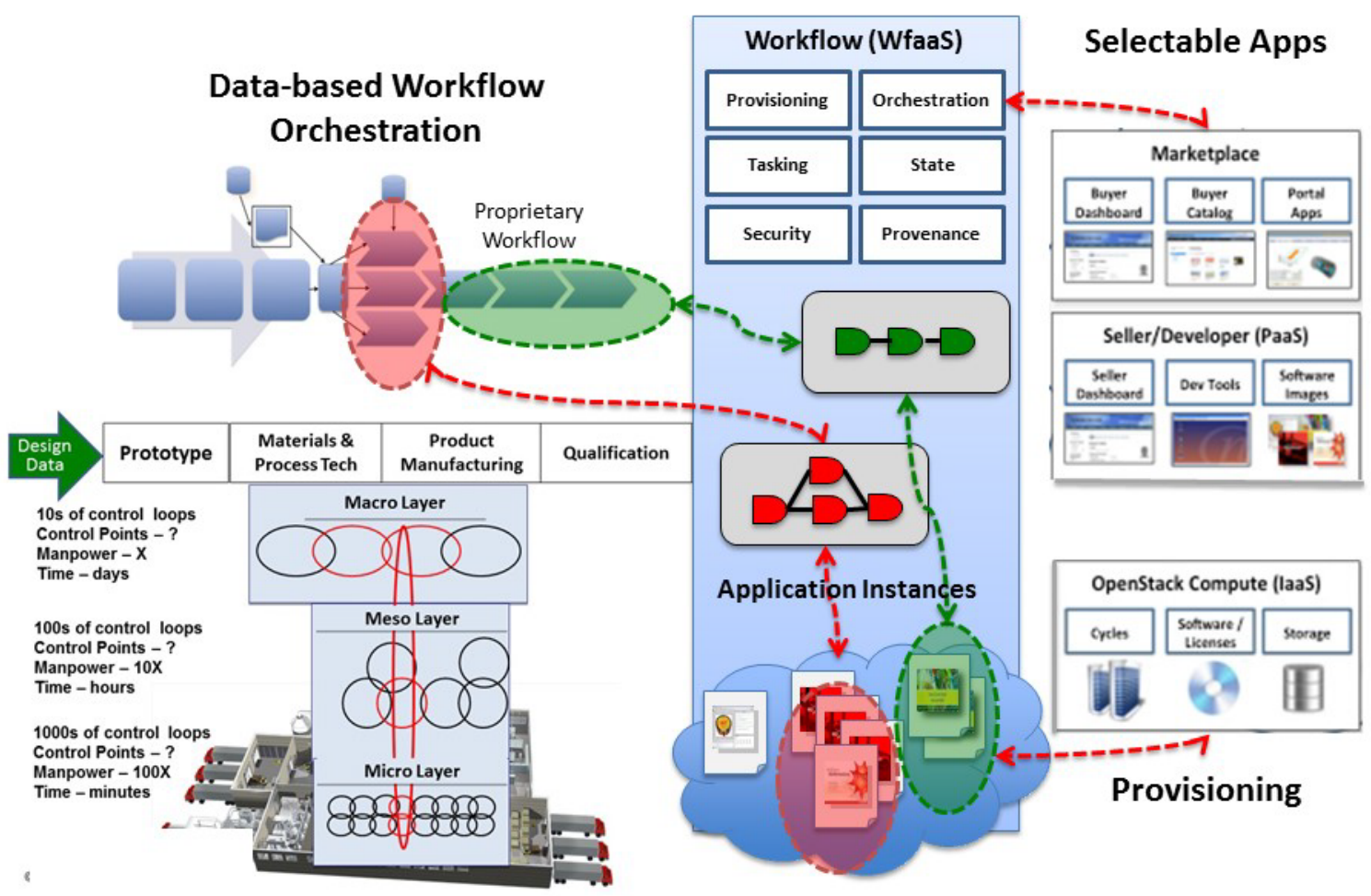

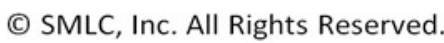

Fig. 1. Workflow-based Smart Manufacturing Platform proposed by the SMLC [14].

possible while enabling interoperability between disparate factory and supplier IT provider platforms. In the section below, we explore how a platform such as the SMLC SM Platform could be used to address challenges in food production supply chains.

\section{Case Study: Improving Production and Supply Chain Efficiency through Early Input Qualification}

In this section, a case study is presented that examines a common manufacturing supply chain issue and shows how the application of smart manufacturing concepts can be used to address the issue, improve manufacturing and supply chain efficiency, and set the stage for further improvements. Input qualification is a part of the overall set of processes, procedures, regulations, and guidelines defined as Good Manufacturing Practices (GMPs) [17]. GMPs are used by food manufacturers and required by federal and state governments to ensure that safe products are the result of the food manufacturing process. From the manufacturer's perspective, this process sits at the junction between the inter-enterprise activities carried out in the supply chain and the intra-enterprise activities necessary to complete product manufacturing. Input qualification involves verifying the quality and provenance of the raw materials used to make a foodbased product and ensuring that GMPs are followed [18]. While federal, state, and local government agencies set the regulations and procedures that must be adhered to, the manufacturer can define and 
require more stringent procedures to be used, both internally and by its suppliers. Many manufacturers take such measures to increase consumer confidence in their products and to provide a marketing advantage against their competitors.

The scope of the scenario examined here is the supply-chain-related activities involved in the acquisition and transport of grain, and the manufacturer's activities undertaken to use that grain in the production of a food product. The scenario covers both the manufacturer's and supplier's activities with respect to the input qualification process. These activities include:

- Verifying that a raw material supplier is following GMPs in the acquisition, storage, handling, and transport of the raw material ${ }^{3}$.

- Identifying the characteristics of a specific raw material lot and assigning it a lot number.

- At the time of delivery to the manufacturing plant, verifying the identity of the raw material lot and the vendor's declaration that GMPs were followed with respect to shipment of the lot.

- Testing the characteristics of a raw material lot and verifying that they meet or exceed local quality standards.

Figure 2 presents the manufacturing supply chain scenario in the form of a Unified Modeling Language (UML) use case diagram [19]. In a use case diagram, the boundary of the system being modeled is indicated by a large rectangle with a brief description of the overall behavior of the system. Use cases define the key activities/functions of the system that together make up its behavior. They are represented in the diagram as ovals containing a brief description of the function of the use case. Associated with a use case may be one or more actors, which are the people and/or hardware or software systems that participate in providing the function defined by the associated use case. Actors are represented in the diagram with a stick figure icon with the name of the person or system under the icon. Actors may be associated with more than one use case and these associations are indicated by a straight line between the actor and its associated use cases. In addition, relationships between use cases may be modeled. The "include" relationship indicates that the function defined by a use case includes the function provided by another use case. This relationship is depicted using a dashed arrow that includes the UML «include» stereotype from a use case to a second use case whose functionality is included in the first. The "extend" relationship indicates that under certain conditions, the function defined by a use case will be extended with additional behaviors defined by another use case. This relationship is depicted using a dashed arrow that includes the UML «extend» stereotype from a use case, to second use case defining some additional function that will take place, and a UML note icon containing the conditions under which the additional function will take place. In the diagram, nine main use cases define the function of the system. Except for the Replan Production use case, the main use cases all are directly associated with one or more actors. Important sub-functions of the main use cases are depicted as separate use cases and associated with the main use cases using the include relationship. Descriptions of the main use cases are provided in Table 1.

The use case diagram in Fig. 2 provides the high level view of the activities that must go on as a part of the food production system and the key stakeholders in the system. A diagram in Fig. 3 shows how the high level use cases are refined into a more detailed view of the same system. In this figure, the people or systems (i.e., the software systems of the plant's or vendor's application infrastructure) that carry out the work described by the use cases are shown, along with the information and physical asset flows between them. For example, the Resource Management system makes use of the company's Enterprise Resource Planning (ERP) application to implement the functionality of the Plan Production and Request Grain Shipment use cases, and the Production Management system uses the Product Lifecycle Management (PLM) and Manufacturing Operations Management (MOM) applications to implement parts of the Make Product and Plan Production use cases. Also, information flows that occur as a result of a grain shipment being deemed (through testing) out of specification are indicated with dashed lines. This is to highlight the actions that must be taken to react to the occurrence of a negative event. The implications to the performance of the plant due to this and other negative events are discussed below.

\footnotetext{
${ }^{3}$ Since this process is complicated and time consuming, it is usually done before a raw material shipment is requested and the vendor only has to sign a "declaration" that they are still following GMPs.
} 


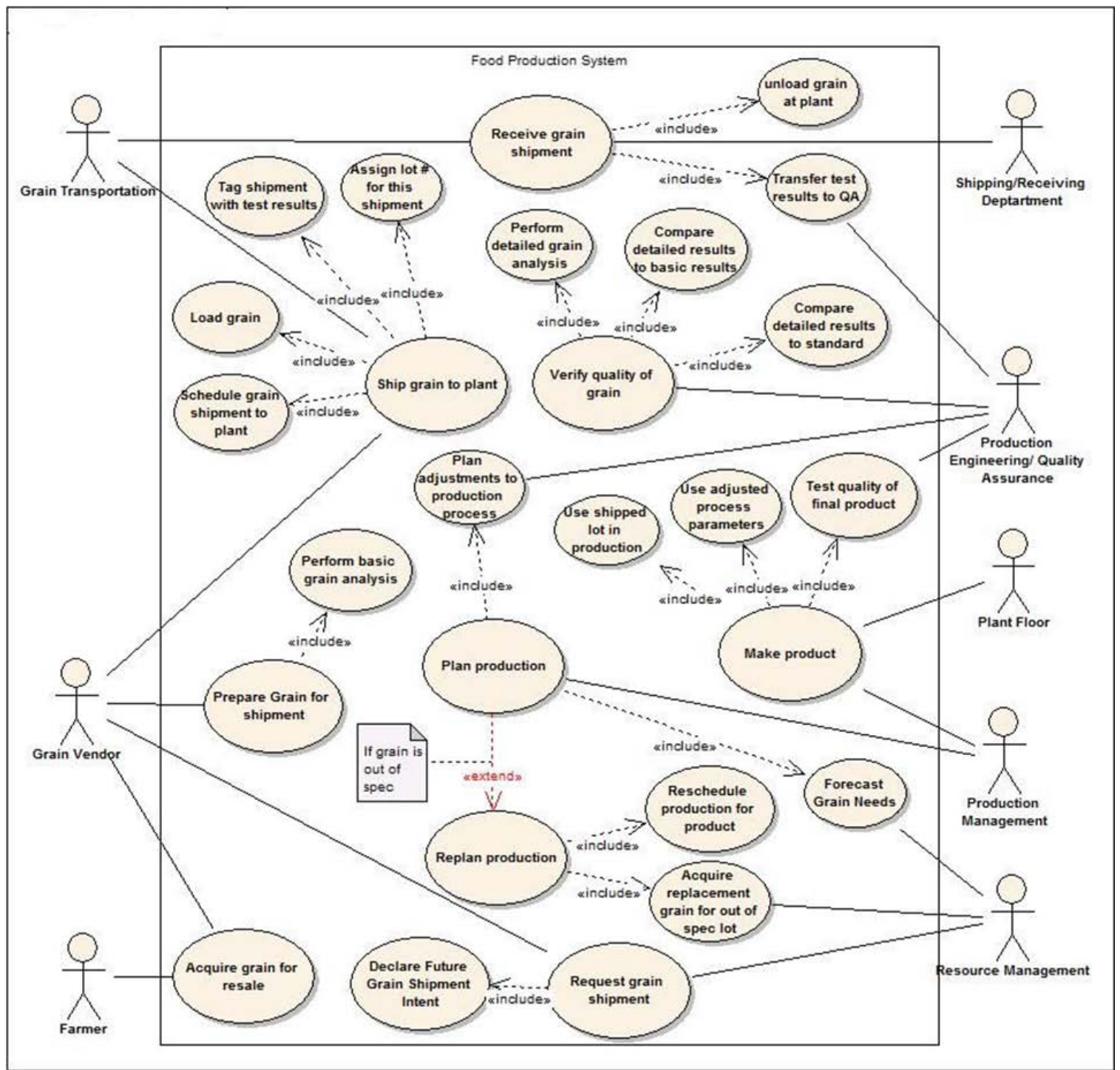

Fig. 2. Use case diagram for an input qualification process of a food production system.

Even though the food production system described above is functionally decomposed in a logical manner and the responses to some adverse conditions (such as re-planning for out of specification grain) accounted for, situations can occur that cause the system to be inefficient or to fail. Responding to adverse situations can cause manufacturers to expend great amounts of time and money, as can implementing procedures to avoid such situations or mitigate their effects. The situations which are of greatest concern to manufacturers are those that cause a delay or halt to production, and those that cause the final product to be of unacceptable quality necessitating that the output of production be discarded. Identifying the precipitating events that lead to these adverse situations can be difficult because the root cause may be many steps earlier in the production process or in the supply chain. 
Table 1. Description of main use cases for the food production system

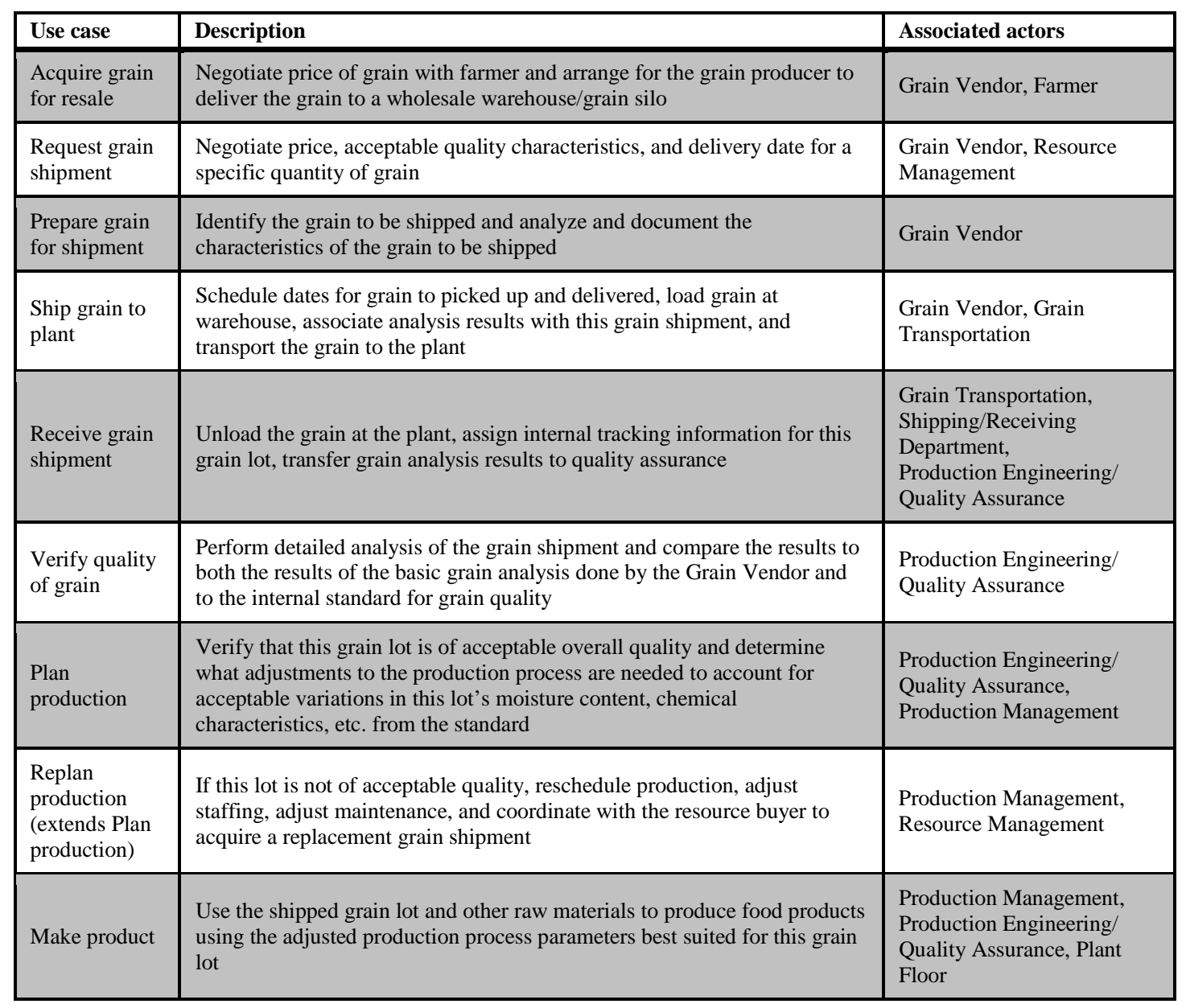

To examine the relationships between failures in the food production system and their root causes, a basic fault tree analysis was done. Fault tree analysis is a technique used for system and reliability engineering of complex systems, and can be applied both retrospectively to understand the causes of failure in existing systems, and, as is the case in this examination, to proactively identify the potential causes of system failure so that corrective actions can be devised and implemented [20]. To construct a fault tree, an adverse event (i.e., the fault) is connected to intermediate precipitating events with AND gate or OR gate symbols indicating the logical relationships between the events. Each intermediate event is similarly connected logically with its precipitating events until the basic events (the root causes) related to the ultimate fault are determined.

In Fig. 4, a fault tree for the food production scenario is presented that focuses on the faults/events that would need to occur for the system to fail in its goal of producing quality products on time. The events that are the root causes of the main fault are labeled A through J. The scope of the fault tree is limited to the effects of the input qualification process on the overall supply chain and production system; therefore the grain transportation failure branch of the tree is not developed or labeled. 


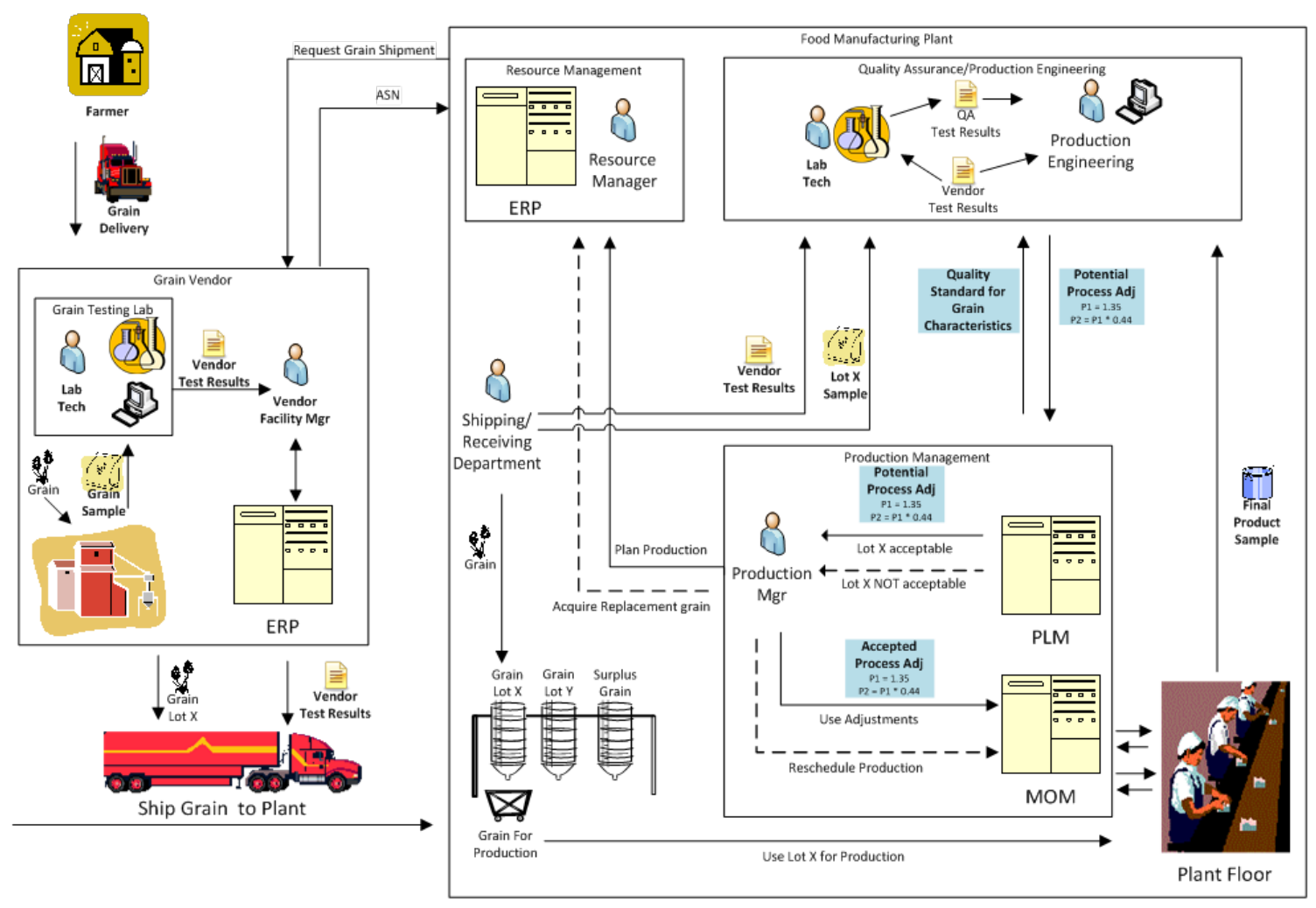

Fig. 3. Software application and actor interactions involved in the food production use case.

To investigate how the events that cause faults in the food production system relate not only to the process represented by the system but also to the infrastructure supporting that process, a qualitative analysis was performed on the fault tree. First the minimal cut set for the tree was developed, which is a list of individual or combined root causes whose occurrence is sufficient to cause the main fault. Next, for each root cause or combination of root causes, potential corrective actions that could be taken to eliminate or alleviate the problem are listed. Finally, for each potential corrective action, barriers to implementing the corrective actions are listed. The results of this analysis are presented in Table 2.

Examining all of the information about the food production process, its supporting infrastructure, and how some seemingly minor events can cause major adverse outcomes for production, three inherent deficiencies in the process can be identified. First, the food production company is in a no-win situation with respect to verifying the grain at delivery and having enough time to alter its production plans if the grain is out of specification. It can be assumed that since the grain vendor has been pre-qualified this event is rare, but when it occurs the consequences are severe for the company. Also, always keeping sufficient surplus grain on hand (for an event that is assumed to be rare) is wasteful and costly. Second, the application infrastructure supporting the process is insufficiently integrated to enable a smooth exchange of important information, such as test results, from sub-process to sub-process. This leads to an overall process with several manual exchanges of key information where delays or loss of the information can occur and lead to system failure. Third, the tasks that make up the overall food production process are not sufficiently monitored, managed, and automated. While the lack of automated task management may be due, in part, to the application infrastructure integration issue mentioned above, this shortcoming further opens the possibility for minor events to cause major problems. Further note that these deficiencies exist while the food production company attempts to rigorously follow good manufacturing practices such as documenting all procedures to be followed as a part of the process, manually monitoring production events, self-auditing company and vendor compliance to procedures, etc. 


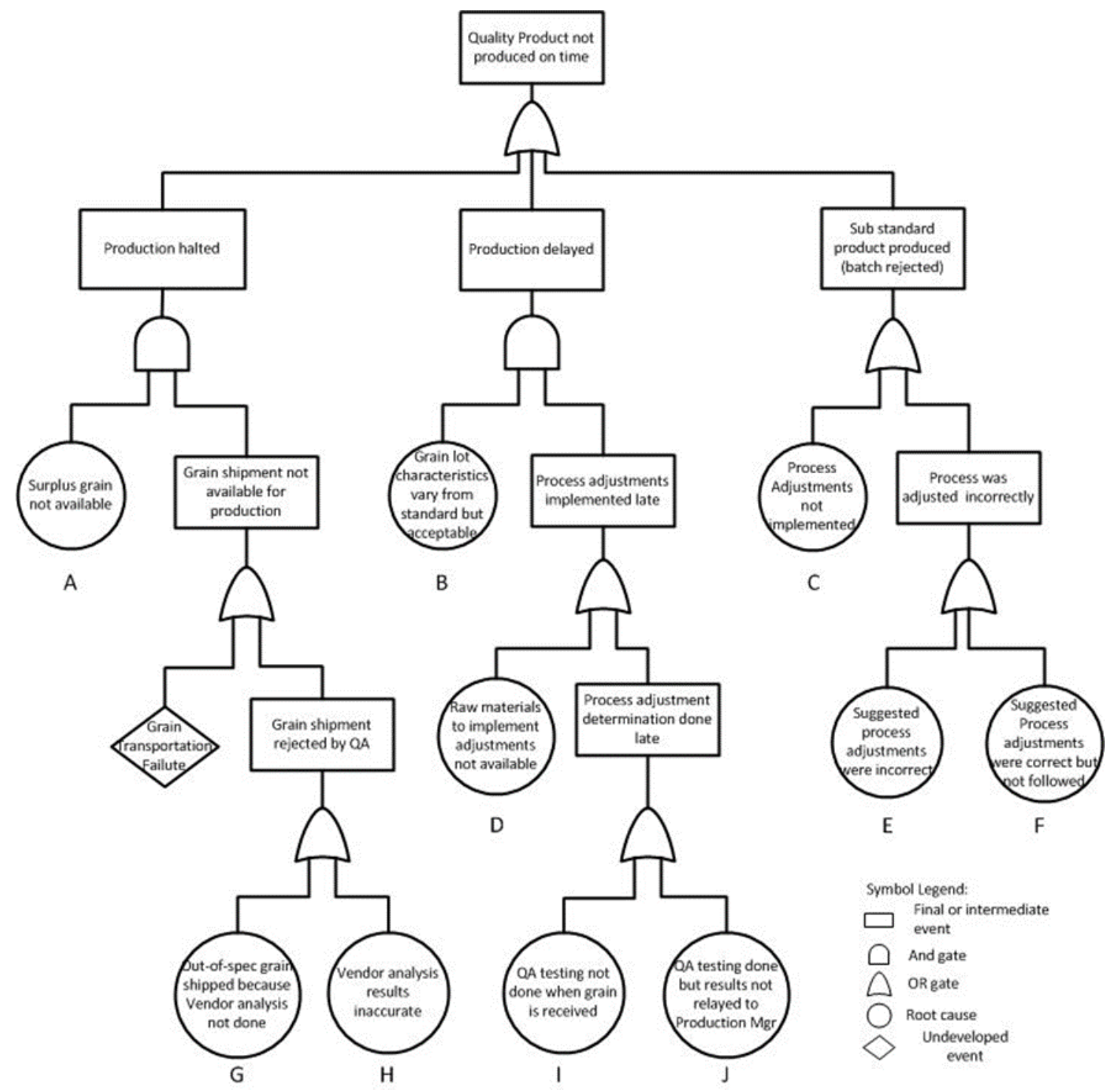

Fig. 4. Fault tree describing problems that affect the food production system.

To avoid the significant system faults described above, the food production process and the infrastructure supporting it must be changed. A means must be found to better integrate the applications that make up the food production company and supplier infrastructures, to better monitor, manage, and automate the sub-processes of the overall food production process, and to eliminate the situation where outof-specification grain is delivered for production. In essence, the system must be made to be "smarter." In the sections below, how smart manufacturing concepts will be applied to the food production systems to address its current deficiencies will be discussed. A key means for applying these concepts will be the integration of the food production system's processes and infrastructure with an instance of the smart manufacturing platform described in a previous section. 
Table 2. System fault root causes, possible corrective actions, and impediments to their implementation

\begin{tabular}{|c|c|c|}
\hline $\begin{array}{l}\text { Root cause(s) of the } \\
\text { system fault }\end{array}$ & $\begin{array}{l}\text { Corrective actions that could mitigate } \\
\text { the problem }\end{array}$ & $\begin{array}{l}\text { Impediments to corrective action } \\
\text { implementation }\end{array}$ \\
\hline AG & $\begin{array}{ll}- & \text { Increase surplus grain } \\
- & \text { Stop out-of-spec grain before shipment }\end{array}$ & $\begin{array}{ll}\text { - } & \text { Cost prohibitive and inefficient } \\
\text { - } & \text { Unable to verify vendor testing results before } \\
\text { shipment }\end{array}$ \\
\hline $\mathbf{A H}$ & $\begin{array}{ll}- & \text { Increase surplus grain } \\
- & \text { Stop out-of-spec grain before shipment }\end{array}$ & $\begin{array}{ll}- & \text { Cost prohibitive and inefficient } \\
\text { - } & \text { Unable to verify vendor testing results before } \\
\text { shipment }\end{array}$ \\
\hline BD & $\begin{array}{ll}- & \text { Increase surplus raw materials } \\
\text { - } & \text { Determine adjustments sooner }\end{array}$ & $\begin{array}{ll}- & \text { Cost prohibitive and inefficient } \mid \\
\text { - } & \text { Unable to determine adjustments until grain is } \\
\text { delivered }\end{array}$ \\
\hline BI & $\begin{array}{l}\text { Automate/monitor the test, analysis, } \\
\text { process adjustment generation tasks }\end{array}$ & $\begin{array}{ll}\text { - } & \text { QA and production management systems not } \\
\text { fully integrated }\end{array}$ \\
\hline BJ & 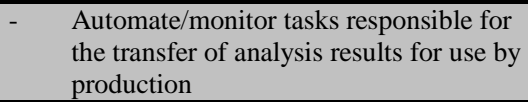 & $\begin{array}{l}\text { - QA and production management systems not } \\
\text { fully integrated }\end{array}$ \\
\hline C & $\begin{array}{l}\text { - } \begin{array}{l}\text { Automate/monitor tasks for the } \\
\text { implementation of process adjustment } \\
\text { into production }\end{array} \\
\end{array}$ & $\begin{array}{l}\text { - QA and production management systems not } \\
\text { fully integrated }\end{array}$ \\
\hline $\bar{E}$ & $\begin{array}{ll}\text { - } & \text { Validate results with further } \\
\text { analysis/simulation }\end{array}$ & $\begin{array}{ll}\text { - } & \text { Access to higher fidelity analysis/simulation } \\
\text { applications limited }\end{array}$ \\
\hline $\mathbf{F}$ & $\begin{array}{ll}\text { - } & \text { Automate/monitor tasks for the } \\
\text { implementation of process adjustment } \\
\text { into production }\end{array}$ & $\begin{array}{l}\text { - QA and production management systems not } \\
\text { fully integrated }\end{array}$ \\
\hline
\end{tabular}

A platform for smart manufacturing such as described above has two primary capabilities that can be used to reduce the risk of the faults in the food production use cases. These capabilities are: (1) management of workflows for business and manufacturing processes within the food production enterprise and its supply chain and (2) injection of information technology via Apps that integrate the workflows with existing systems, personnel, and processes. The Apps automate functions that were previously done manually, or provide new capabilities that can improve existing processes or enable new ones. Below, a description of how to use a Smart Manufacturing Platform (SM Platform) to improve the system described by the food production use case is presented, including what systems and processes would result, and how this would reduce the risk of faults and insure more efficient production.

The Smart Manufacturing Platform described here is largely the platform envisioned by the Smart Manufacturing Leadership Coalition (SMLC) and introduced in Sec. 3 of this paper. It is middleware that provides standard services and components for design time and run time that users and third parties can use to build new applications and services to automate or enhance manufacturing processes. Federated workflow execution and orchestration is the primary standard runtime service native to the platform. Data and event services may also be provided. An "App store" will provide access to both purpose-built and customizable $3^{\text {rd }}$ party applications that users could purchase to later perform specific functions either for run time or design time. Users could then use toolkits to build their own workflows that stitch together functions provided by these Apps, by existing applications or processes within the enterprise, and by new capabilities built to work with the platform to perform complex business processes. The platform will provide a repository where user-developed workflows and Apps could be stored for later execution. This repository will also contain the $3^{\text {rd }}$ party Apps that the enterprise has purchased. The SM Platform will provide a standard runtime environment in which workflows and Apps can be executed, yet it will be capable of executing them in different computing environments while keeping this diversity largely hidden from the executing code. Potential locations for this computing infrastructure include within a factory, within a manufacturer's computing center, within a private cloud, or within a public cloud. The federated workflow capability of the platform allows executing components to be distributed among multiple such locations simultaneously. Location of execution could be driven by location of a key resource, by the quality of service (QoS) needs of particular functions (such as latency or availability), or by organizational policy. 
The food manufacturer from the food production scenario would need to create a number of Apps and workflows to automate the processes that have been outlined in the use cases. Table 3 enumerates the components that would populate the repository of an SM Platform to automate the activities described in this scenario.

Table 3. Descriptions of executable user components for the platform

\begin{tabular}{|l|l|l|l|}
\hline Component name & Type & Description & Platform \\
\hline $\begin{array}{l}\text { Remote eCOA } \\
\text { Server }\end{array}$ & App & $\begin{array}{l}\text { Platform App that Receives and routes electronic certificate of } \\
\text { analysis (eCOA) for a grain shipment to workflow execution } \\
\text { engine to spawn shipment approval workflow }\end{array}$ & SM Platform \\
\hline $\begin{array}{l}\text { Remote eCOA } \\
\text { Client }\end{array}$ & App & $\begin{array}{l}\text { Web or mobile client used by grain vendor's laboratory to submit } \\
\text { grain analysis results to the manufacturer via Remote eCOA } \\
\text { Server App }\end{array}$ & $\begin{array}{l}\text { Web browser or } \\
\text { commercial } \\
\text { mobile platform }\end{array}$ \\
\hline Grain Assessment & App & $\begin{array}{l}\text { App which compares eCOA against standard to evaluate grain } \\
\text { shipment for production }\end{array}$ & SM Platform \\
\hline $\begin{array}{l}\text { Process } \\
\text { Reformulation }\end{array}$ & App & $\begin{array}{l}\text { App which determines process parameters for production with } \\
\text { grain shipment }\end{array}$ & SM Platform \\
\hline $\begin{array}{l}\text { Shipment } \\
\text { Approval }\end{array}$ & Workflow & $\begin{array}{l}\text { Workflow process that orchestrates the evaluation, acceptance, } \\
\text { and process parameter generation for a grain shipment }\end{array}$ & SM Platform \\
\hline $\begin{array}{l}\text { Source Material } \\
\text { for Production }\end{array}$ & Workflow & Overarching workflow acquiring source materials for production & SM Platform \\
\hline Receive shipment & Workflow & $\begin{array}{l}\text { Workflow orchestrating steps to receive and process a grain } \\
\text { shipment }\end{array}$ & SM Platform \\
\hline
\end{tabular}

Figure 5 illustrates the SM Platform, its executable user components, and the actors and systems within the enterprise with which the user components interact to support the supply chain management and production processes in the food production use cases. The right side of the figure illustrates flexibility for deploying the active components executed by the platform both in terms of location and kinds of computing resources. A large capital investment is not necessary. This allows adoption of SM solutions to be evolutionary rather than revolutionary. Small investments can be made (automating a single use case for instance) to prove the worth of the technology and familiarize users and IT support staff with it. The flexibility also enables technology to be injected in technologically poor environments. For the food production use cases this allows the manufacturer to extend tight integration to its suppliers. This in turn allows the manufacturer to get the right information sooner, enabling both earlier input qualification and production parameter adjustment, substantially reducing the risk of lost production time, or the production of unacceptable products. Details of information flows within the system are described in the next section.

In Fig. 6 a UML collaboration diagram is used to present a detailed view of how the SM Platform can be used to implement the Source material for production and the Shipment approval workflows. It shows how information is sent between the components of the system and how the sequencing of the exchanges enables the inter-enterprise production network to accomplish its mission. In this scenario, the two workflows (that are executed as a part of the SM platform) collaborate with the vendor's systems to request a grain shipment, have the vendor test a sample of the grain, and to send the results back to the OEM for verification (messages 1 through 1.11 in black). If the grain is suitable for use in production, the vendor is notified that the grain is acceptable, adjustments to the production process to account for grain characteristic variability are determined, and this information is stored in the production systems for use when the grain arrives and is used in production (messages 3 through 3.6 in green). If the grain is found to be unsuitable for use in production, the vendor is instructed to not ship the grain to the OEM and a new request for grain is made (messages 2 through 2.3 in red). Execution of the Apps used by these workflows is also controlled by the platform. Apps perform the functions of receiving the vendor's lab results, aiding in product assessment, and determining adjustments that can be made to production parameters. 


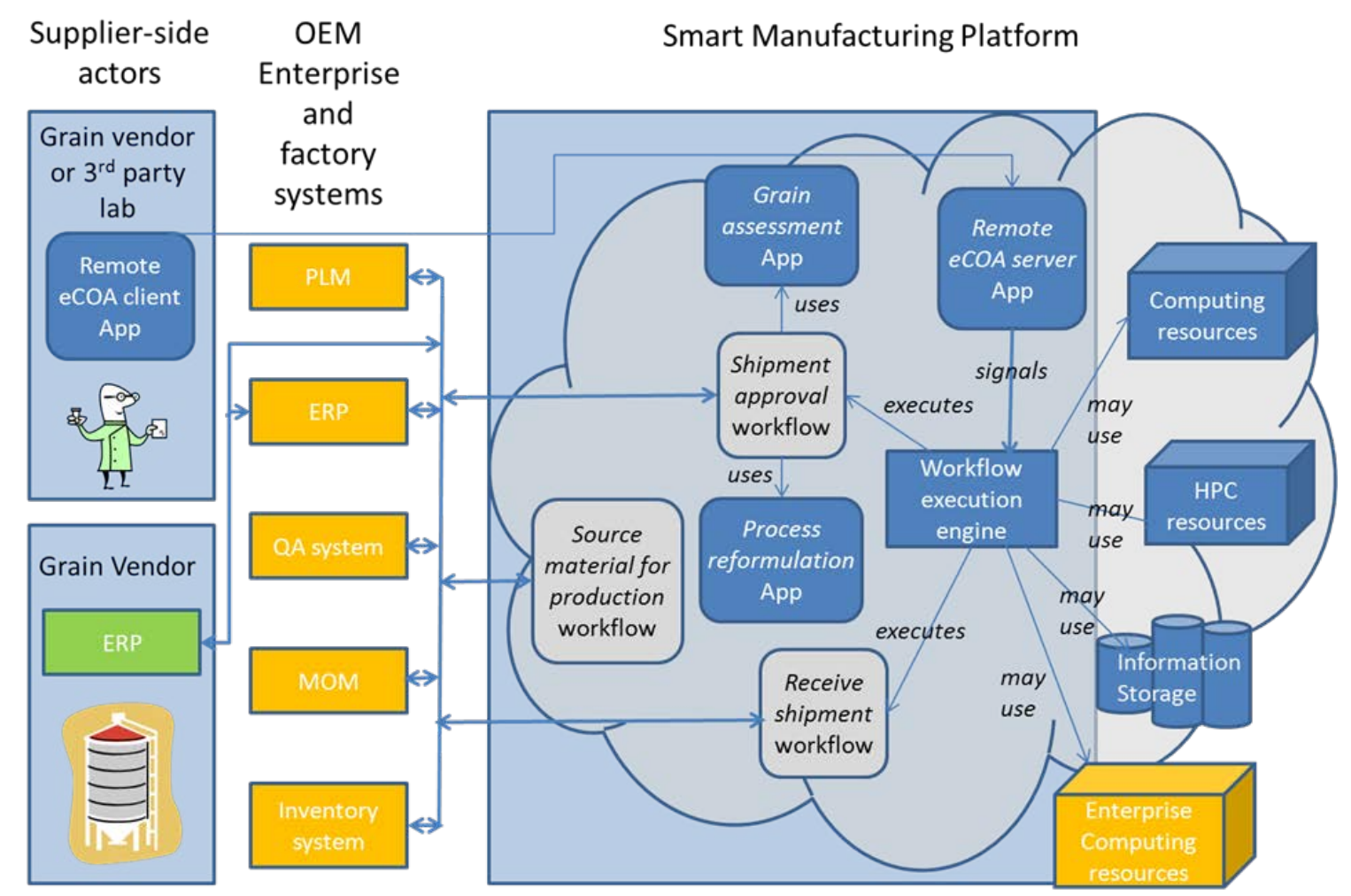

Fig. 5. SM Platform with its runtime components and the systems of the food production system.

The OEM can gain several benefits by deploying the SM Platform-enabled scenario described above. The Remote eCOA client App ensures that the right information for evaluation is gathered, captures it in a form that can be processed in an automated fashion, and delivers it much earlier in the production planning process than is possible with the original system. When coupled with the workflow execution capabilities of the SM Platform, many functions that are performed in the original food production scenario after receipt of the grain shipment can be performed much earlier, more consistently, and potentially with better results (due to the increased time available before the use of the grain is required and the ability to consistently apply best practices and employ the best knowledge/skills available for the job). In comparison to the original food production system (Fig. 2) the Source Material for Production and Shipment Approval workflows monitor and automate the pre-verification of the quality of the grain, the sourcing of new grain shipments if the current shipment is unacceptable, and the planning and storage of process adjustments for acceptable grain shipments. This will not eliminate the need for testing of grain when it is received (which will be performed by the Receive shipment workflow), because GMP requires that testing be verified and because changes can occur to grain in shipment and storage. It does, however, reduce risk from unacceptable input grain through early remote testing, reduce the time needed between grain receipt and production, and improve the quality of processes used for production. This will result in a considerable reduction in the cost to produce and lead to a more consistent, higher quality product.

The advantages to employing a workflow-based SM Platform as has been described above are:

- Ability to capture Good Manufacturing Practices and other best practices in an executable form. This allows enforcement of these practices and a record of their execution for verification or later assessment for sleuthing of problems or assessment for future improvement.

- Orchestration of both manual and automated processes allowing integration across previously separate domains, organizations, and vendor ecosystems. This provides consistent control, visibility, and record keeping previously unavailable. 


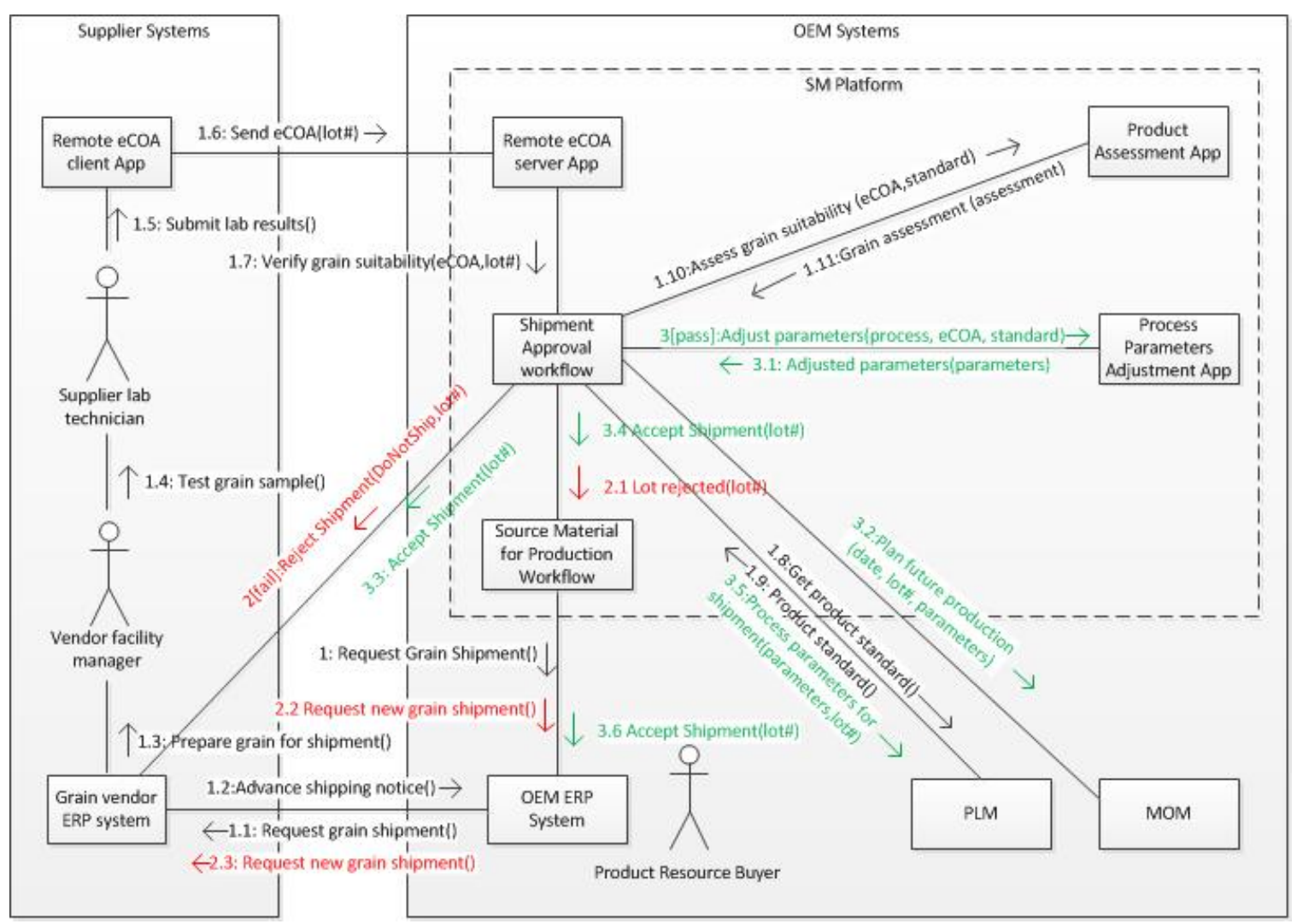

Fig. 6. System component collaboration for Shipment Approval and Source Material for Production workflow realization.

- Location independence allowing flexibility in deployment of components and processes, change of topology without disruption, and ability to use the best resources for a particular job (whether that be people, applications, or equipment).

- Ability to encapsulate differences in implementation at different layers of workflow enabling smoother and less costly transitions to newer technologies or approaches. This, in turn, gives food manufacturers flexibility to deploy the technologies they need to address changing business needs.

\section{The Need for Standards to Support Smart Manufacturing}

To fully address the problems in the food production network due to ingredient variability issues, standard means for describing the key elements of the problem and the solution need to be developed. Standards are needed to unambiguously and uniformly specify ingredient characteristics and acceptable variability; to specify format and content for reporting and/or exchanging the results of ingredient characteristics analysis (COA); and to specify the amount, means of transport, conditions of transport, and chain of responsibility for ingredient lots delivered for production. Presently, organizations such as agXML [21], ANSI ASC X12 [22], the Open Applications Group [23], and UN/CEFACT [24] address portions of these needs, often for specialized industries or product types. There is also ongoing work at UN/CEFACT (e-Labs observation reporting) [25] and in the Open Applications Group (Quality Content Working Group) [26] to expand support for specification of tests/inspections and reporting results. However, none of these organizations currently provide robust and comprehensive support for all these needs, and it would be a challenge to stitch parts together from existing standards for the complete view needed to support a genealogical view of a product across its entire lifecycle. 
Standards also need to be developed to ensure the applications and infrastructure supporting SM systems are open and interoperable. These standards include specifications for the capabilities of, and interfaces to the components of the SM Platform and other SM infrastructure applications. Such standards are also critical for SM applications and infrastructure components to be integrated with elements of the existing infrastructure and applications supporting the manufacturing enterprise.

\section{Summary}

Many of the problems that food product manufacturers must face daily can be traced back to issues with input ingredient variability. Food product manufacturers must continually adjust their products' recipes to account for the expected characteristics of ingredients and manage their supply chain to ensure acceptable ingredients are available. Maintaining quality and efficiency in the face of dynamic ingredient variation requires orchestrating processes that use data and functions in two very distinct parts of the business: (1) product design/engineering, which produces and controls the specifications of the product, its ingredients and how the product is produced and (2) planning and production operations, which is responsible for planning and executing production of a quality and consistent product meeting product specifications. The smart manufacturing approach and Smart Manufacturing Platform infrastructure will be particularly well suited to this, as it will support the development of new processes that can be layered onto multiple existing systems and functions without major disruption. These new processes can then be easily adapted to changes in the underlying systems, allowing best practices to be maintained even as underlying systems evolve.

In this paper, a case study was presented that shows how smart manufacturing can be used to address the problem. The concept of smart manufacturing and how that concept can be used to enable more efficient manufacturing operations and better products was discussed. Information about the design and capabilities of a smart manufacturing platform were also presented. The case study showed how efficiency could be improved and production risks reduced for the production operations and supply chain supporting the food product manufacture. Needs for standards were identified both for supporting exchange and integration of ingredient and product characteristic information, and to insure interoperability of Smart Manufacturing components and infrastructure.

\section{Acknowledgments}

This work was funded in part by Cooperative Agreement \#70NANAB12H219 between NIST and UCLA.

\section{References}

[1] FDA Food Safety Modernization Act, Public Law 111-353, U.S. Statutes at Large 124 (2011): 3885-3973.

[2] United Nations Statistical Division, Value Added by Economic Activity, at current prices - US Dollars, all countries, National Accounts Main Aggregate Database, http://unstats.un.org, (December 2014) [Accessed (October 21, 2015)].

[3] The White House, Office of the Press Secretary, President Obama to Announce New Efforts to Support Manufacturing Innovation, Encourage Insourcing, http://www.whitehouse.gov/the-press-office/2012/03/09/president-obama-announce-newefforts-support-manufacturing-innovation-en, (March 9, 2012) [Accessed (October 22, 2015)].

[4] National Institute of Standards and Technology, Systems Integration Division, SMSDA, Smart Manufacturing Systems Design and Analysis Program, National Institute of Standards and Technology, http://www.nist.gov/el/msid/syseng/smsda.cfm, (October 1, 2013) [Accessed (October 22, 2015)].

[5] National Institute of Standards and Technology, Systems Integration Division, SMOPC, Smart Manufacturing Operations Planning and Control Program, National Institute of Standards and Technology, http://www.nist.gov/el/msid/syseng/smopc.cfm, (October 1, 2013) [Accessed (October 22, 2015)].

[6] L. Fountaine, The Journey Towards SMART: The Changing Face of Manufacturing, http://smartmanufacturing.com/2012/06/, (June 11, 2012) [Accessed (October 22, 2015)].

[7] S. S. Shipp, N. Gupta, B. Lal, J. A. Scott, C. L. Weber, M. S. Finnin, and S. Thomas, Emerging Global Trends in Advanced Manufacturing (No. IDA-P-4603), Institute for Defense Analyses, Alexandria, VA, March 2012.

[8] A. Chopra, Insourcing American Jobs: The Importance of "Smart” Manufacturing, Broadband, and IT, http://www.whitehouse.gov/blog/2012/01/14/insourcing-american-jobs-importance-smart-manufacturing-broadband-and-it, White House, (January 14, 2012) [Accessed (October 22, 2015)]. 
[9] Y. Koren, The global manufacturing revolution: product-process-business integration and reconfigurable systems, www.Wiley.com, (2010). http://dx.doi.org/10.1002/9780470618813

[10] McKinsey Global Institute, McKinsey Operations Practice, Manufacturing the future: The next era of global growth and innovation, McKinsey\&Company, http://www.mckinsey.com/insights/manufacturing/the_future_of_manufacturing, (November 2012) [Accessed (October 22, 2015)].

[11] J. T Macher and D. C. Mowery (Eds.), Innovation in global Industries: US firms competing in a New World (collected studies), National Academies Press, http://www.nap.edu/, (May 12, 2008) [Accessed (October 22, 2015)].

[12] A. Regalado, Manufacturing in the balance, MIT Technical Review, http://www.technologyreview.com/news/509231/manufacturing-in-the-balance/, (Jan 3, 2013) [Accessed (October 22, 2015)].

[13] McKinsey Global Institute, McKinsey Operations Practice, Disruptive technologies: Advances that will transform life, business, and the global economy, McKinsey\&Company, http://www.mckinsey.com/insights/business_technology/disruptive_technologies, (May 2013) [Accessed (October 22, 2015)].

[14] J. F. Davis, J. Wetzel, and B. Graybill, Smart Manufacturing, Real-time Networked Information Workflows and Enterprise Performance, Proceedings of the 3rd International Conference on Sustainable Chemical Product and Process Engineering, (2013).

[15] J. F. Davis, T. Edgar, J. Porter, J. Bernaden, and M. Sarli, "Smart manufacturing, manufacturing intelligence and demand, dynamic performance”, Computers \& Chemical Engineering, Vol. 47, pp. 145-156 (2012). http://dx.doi.org/10.1016/j.compchemeng.2012.06.037

[16] Object Management Group, Workflow Management Facility Specification, V1.2, Object Management Group, http://www.omg.org/spec/WfMF/1.2/, (May 2000) [Accessed (October 22, 2015)].

[17] U.S. Food and Drug Administration, Current Good Manufacturing Practices (CGMPs), U.S. Food and Drug Administration, http://www.fda.gov/Food/GuidanceRegulation/CGMP/default.htm, (July 14, 2015) [Accessed (October 22, 2015)].

[18] P. J. Shadle, “The Art of Raw Materials and Supplier Qualification”, BioProcessing Journal, Vol. 3, No. 6, pp. 43-46, (2004).

[19] G. Schneider and J. P. Winters, Applying use cases: a practical guide, Pearson Education, Boston, Massachusetts, (2001).

[20] W. Vesely, M. Stamatelatos, J. Dugan, J. Fragola, J. Minarick III, and J. Railsback, Fault tree Handbook with Aerospace Applications, Version 1.1., NASA Office of Safety and Mission Assurance, NASA HQ, http://www.hq.nasa.gov/office/codeq/doctree/fthb.pdf, (August 2002) [Accessed (October 22, 2015)].

[21] agXML http://www.agxml.org [Accessed (December 15, 2015)].

[22] American National Standards Institute (ANSI) Accredited Standards Committee (ASC) X12, http://www.x12.org/about/ [Accessed (December 15, 2015)].

[23] Open Applications Group, http://www.oagi.org/ [Accessed (December 15, 2015)].

[24] UN Centre for Trade Facilitation and E-business (UN/CEFACT), http://www.unece.org/cefact [Accessed (December 15, 2015)].

[25] UN Centre for Trade Facilitation and E-business, Business Requirements Specification, electronic laboratory observation reporting messages, http://www1.unece.org/cefact/platform/display/CNP/e-Laboratory+observation+report+message (May 21, 2014) [Accessed (December 15, 2015)].

[26] Open Applications Group, Quality Content Working Group, http://www.oagi.org/dnn2/OurCommunity/WorkingGroups.aspx [Accessed (December 16, 2015)]

About the authors: Frank Riddick is a Computer Scientist in the Systems Engineering group of the Systems Integration Division of the Engineering Laboratory at NIST. He has participated in research and authored over 50 technical papers relating to distributed simulation, manufacturing simulation integration, information modelling, and smart manufacturing.

Evan Wallace is an electronic engineer in the Systems Engineering group of the Systems Integration Division of the Engineering Laboratory at NIST. At NIST, his focus has been on models, languages, technologies and standards for system integration for manufacturing and other technical domains with a concentration on ontologies and conceptual modeling, and has been involved in many standards efforts supporting these areas in ISO, ISA, OMG and the W3C. His current responsibilities include investigating architectures, standards, and practices to enable smart manufacturing.

Jim Davis is Vice Provost IT \& CTO with broad responsibilities focused on UCLA's academic research and education mission but building on his past position as Associate Vice Chancellor \& CIO. He is a Professor in the Department of Chemical and Biomolecular Engineering at UCLA with expertise in data analysis, decision support, and intelligent systems. Jim is also a board member and one of the founding members of the Smart Manufacturing Leadership Coalition (SMLC), a non-profit organization committed to improving manufacturing competitiveness through the adoption of smart manufacturing technology.

The National Institute of Standards and Technology is an agency of the U.S. Department of Commerce. 